\title{
Clonal selection of Corymbia for energy and charcoal production
}

\author{
Letícia Costa Peres ${ }^{1}$ Angélica de Cássia Oliveira Carneiro ${ }^{1}$ Clarissa Gusmão Figueiró ${ }^{1}$ Lucas de Freitas Fialho ${ }^{1 *}$ \\ Marcela Ferreira Gomes ${ }^{1}$ Brígida Maria dos Reis Teixeira Valente ${ }^{1}$ \\ ${ }^{1}$ Universidade Federal de Viçosa, Avenida Peter Henry Rolfs, s/n - Campus Universitário, Viçosa-MG, 36570-900 \\ *Author for correspondence: 1.freitasfialho@gmail.com
}

Received: April 2019 / Accepted: September 2019 / Published: September 2019

\begin{abstract}
The genus Corymbia appears as an option to produce a better quality charcoal. When considering several characteristics of wood and charcoal, the selection of genotypes through multivariate analysis can be a solution when multiple variables influence the result. The aim of this study was to characterize eight genotypes of Corymbia citriodora $\mathrm{x}$ Corymbia torelliana for energy and charcoal production, to group and indicate the genetic materials with highest potential. The wood's basic density, higher heating value and energy density was determined, and the latter was used to group them by the Scott-Knott test; group 1 was appointed for energy generation. The wood was carbonized, and the charcoal yield, apparent density, fixed carbon content, friability, higher heating value, ash content, fixed carbon yield and energy density were determined. Principal component analy sis was performed, considering the variables friability, charcoal yield and energy density. Principal component 3 was chosen, as the representation of the ideal genetic material for charcoal production. The scores were calculated, and genetic materials III, VI and VIII were selected for charcoal production.
\end{abstract}

Keywords: Yield, principal component analy sis, Scott-Knott test

\section{Introduction}

As plantações florestais como fornecedoras de matériaThe world is dependent of a non-sustainable energy matrix, based mainly in the use of fossil fuels, which results in a high emission of greenhouse gases to the environment. An alternative to these fuels is the use of biomass, a renewable fuel (Canadell \& Schulze 2014). In this context, the production of planted forests can be an important ally to reduce greenhouse gases emission (Welfle 2017).

Brazil is known worldwide for its forest productivity. This is associated with the production of quality raw materials from efficient breeding programs. The genus Eucalyptus is the main one used in the segment of planted forests, due mainly to its rapid growth and adaptability to the Brazilian edaphoclimatic conditions. However, due to the occurrence of diseases, pests and water deficit, it is necessary that new genetic materials are developed to ensure the continuity of this productivity, such as the hy brids of Corymbia citriodora $\mathrm{x}$ Corymbia torelliana (Wendling et al. 2015). These hybrids, in general, have shown a high growth and high resistance to these adversities, in comparison with usually planted species. In addition, their higher basic density of wood is a fundamental property when the objective is the production of energy .

Therefore, the selection of the superior genotype material is necessary to obtain high quality raw materials that are suitable for the final use. As the number of variables to be interpreted increases, their analysis through univariate statistics becomes more complex, due to characteristics of the most used tests, such as group overlap. The Scott-Knott test has the advantage of grouping without overlapping.
Another toll to be used in the selection is the multivariate analy sis, initially used only in the areas of psychology, social sciences and biology (Granato et al. 2013), has great application in cases where several factors influence the result, with different weights, and can be a solution when more than one variable influences the end result. Therefore, the aim of this study was to characterize genotypes of Corymbia citriodora x Corymbia torelliana for energy and charcoal production, as well as grouping and indicating the genetic materials with the highest production potential.

\section{Materials and Methods}

This study data proceeded from a commercial plantation of a forestry company, in the municipality of Dionísio, state of Minas Gerais. Eight different genetic materials were analy zed at seven years of age, with three trees for each clone. The site presents average annual precipitation of $1900 \mathrm{~mm}$, relative humidity $73 \%$, average temperature of $20,2^{\circ} \mathrm{C}$ (Max: $30,2^{\circ} \mathrm{C}$, Min: $11,8^{\circ} \mathrm{C}$ ), altitude of $450 \mathrm{~m}$ and vegetation typical of Atlantic forest. The materials were planted in yellow red latosol, at a spacing of 3,0 x 2,5 m.

The wood's basic density was determined according to Alves et al. (2017). The wood's higher heating value (HHV) was determined according to ASTM D240-02 (2002), using dry grinded sifted material, with particle size between 40 and 60 mesh, in an adiabatic calorimeter. The wood's energy density was obtained by multiplying basic density and the HHV of wood.

The carbonization was performed in a muffle oven, using approximately 350 grams of wood in a metallic recipient. The temperature was controlled manually, with increments of $50^{\circ} \mathrm{C}$ every 30 minutes, corresponding to a heating rate of $1.67{ }^{\circ} \mathrm{C} \cdot \mathrm{min}^{-1}$. The initial temperature was $100{ }^{\circ} \mathrm{C}$ and the final $450{ }^{\circ} \mathrm{C}$, remaining in this last one for 60 minutes, completing the process with 4,5 hours. The charcoal yield was determined with the equation 1.

Where:

$$
Y_{c}=\left(\frac{W_{c}}{W_{w}}\right) \times 100
$$

Yc $=$ Charcoal yield $(\%)$

$\mathrm{Wc}=$ Charcoal weight

$\mathrm{Ww}=$ Wood weight

Volatile matter and ash of the biomass were determined by ASTM D3175-89a (2001) and ASTM D3174-04 (2010) methodology, reducing the temperature from 750 to $600{ }^{\circ} \mathrm{C}$ in the ash determination. The fixed carbon yield was determined according to equation 2 .

Where:

$$
Y_{f c}=\frac{Y_{c} \times F C}{100-A s h}
$$

Yfc $=$ Fixed Carbon yield $(\%)$

Yc $=$ Charcoal Yield $(\%)$

$\mathrm{FC}=$ Fixed Carbon $(\%)$ 
$\operatorname{Ash}=\operatorname{Ash}(\%)$

The charcoal friability was evaluated in a friability tester for 17 minutes, rotating in $35 \mathrm{rpm}$. The samples were weighted before and after, and the proportion of material lost calculated according to equation 3 .

Where:

$$
F \%=\left(\frac{m_{i}-m_{f}}{m_{i}}\right) \times 100
$$

$$
\begin{aligned}
& \mathrm{F} \%=\text { Friability } \\
& \mathrm{m}_{\mathrm{i}}=\text { initial mass } \\
& \mathrm{m}_{\mathrm{f}}=\text { final mass }
\end{aligned}
$$

The charcoal apparent relative density was determined according to Pereira et al. (2016) using hydrostatic weighing. The higher heating value (HHV) was determined according to ASTM D240-02 (2002), using grinded charcoal, in an adiabatic calorimeter. The energetic density was obtained multiplying the apparent relative density and HHV of the charcoal.

The experiment was set up in a completely randomized design with eight treatments (genetic materials), with three replications (trees), totaling 24 sample units. To select potential genetic materials for energy use, energy density data were subjected to analy sis of variance ( $\mathrm{F}$ test, $\mathrm{p}<0.05)$ and when significant differences were established, the ScottKnott hierarchical clustering algorithm was applied with 5\% significance. To perform this analysis, the Scott-Knott package (SNK) in software R version 3.4.3 was used.

The clones were classified according to the charcoal proprieties, thought principal component analy sis (PCA), in a way to identify, indirectly, the best genetic materials to charcoal production. The PCA was done based on the correlation matrix between the charcoal properties. To calculate the principal components (PC's) was used a PCA algorithm with the software $\mathrm{R}$ version 3.4.3. After the construction of the PC's, the one that presented greater coherence, as the desired properties to produce charcoal, was selected. The scores, which are the values of the PC, were used to rank the genetic materials studied (Rambo et al., 2015).

\section{Results}

The values for wood's basic density varied from 0,51 to 0,60 g. $\mathrm{cm}^{-3}$, and for HHV from 19,11 to $19,61 \mathrm{MJ}_{\mathrm{Kg}}{ }^{-1}$. Energy density, which is the combination of the two previous proprieties, considering that materials with great amount of calorific value can perform poorly for energy purposes due to the lower basic density, as seen in genoty pe VIII (Table 1).

Table 1. Basic density, higher heating value and energy density of the wood.

\begin{tabular}{cccc}
\hline Genetic material & $\begin{array}{c}\text { Basic density } \\
\left({\left.\mathrm{g} . \mathrm{cm}^{-3}\right)}^{-3}\right.\end{array}$ & $\begin{array}{c}\text { Higher heating value } \\
\left(\mathrm{MJ.Kg}^{-1}\right)\end{array}$ & $\begin{array}{c}\text { Energy density } \\
\left(\mathrm{MJ.m}^{-3}\right)\end{array}$ \\
\hline I & $0,56_{(2,53)}$ & $19,19_{(0,28)}$ & $10747,31_{(2,25)}$ \\
II & $0,53_{(5,39)}$ & $19,13_{(0,02)}$ & $10043,09_{(5,41)}$ \\
III & $0,59_{(1,21)}$ & $19,38_{(0,15)}$ & $11338,48_{(1,33)}$ \\
IV & $0,52_{(8,16)}$ & $19,11_{(0,43)}$ & $9935,84_{(8,64)}$ \\
V & $0,60_{(1,18)}$ & $19,42_{(1,13)}$ & $11652,47_{(2,28)}$ \\
VI & $0,51_{(11,20)}$ & $19,39_{(0,93)}$ & $9793,51_{(12,22)}$ \\
VII & $0,53_{(2,67)}$ & $19,37_{(1,24)}$ & $10264,80_{(1,42)}$ \\
VIII & $0,51_{(11,20)}$ & $19,61_{(1,80)}$ & $9900,46_{(12,99)}$ \\
\hline
\end{tabular}

Values in parentheses represent coefficient of variation

The genetic materials were grouped by energy density, by Scott-Knott test. Three different groups were observed: group
1 is composed by genetic materials V and III; group 2 by material I; and group 2 by genetic materials VII, II, IV, VIII and VI (Figure 1). Concerning the use of the wood for energy purposes, group 1 presents the highest energy density values, therefore, they would promote a better use for energy generation.

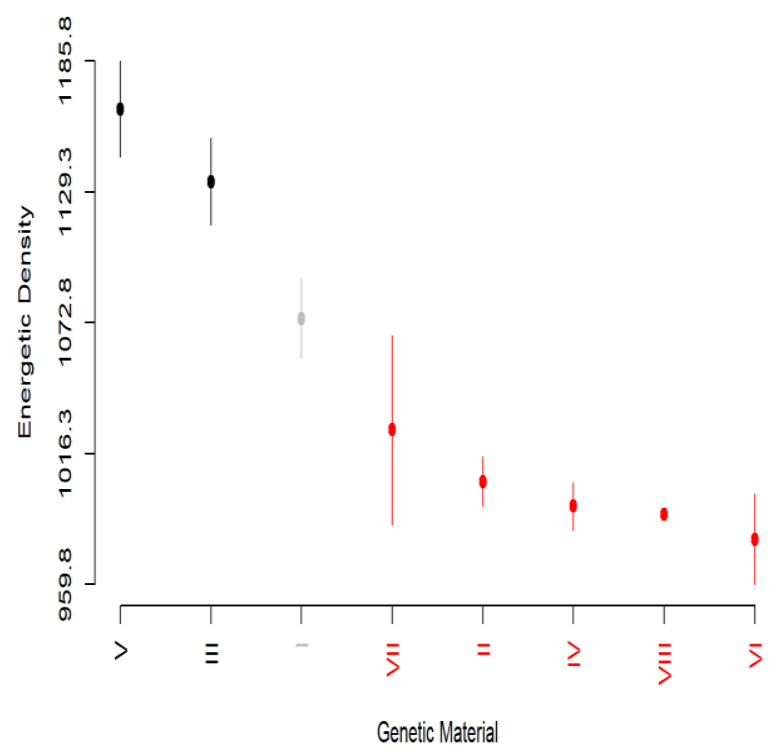

Figure 1. Energy Density of Corymbia citriodora x Corymbia torelliana grouped by the Scott-Knott test.

Table 2 presents the results for the charcoal properties of each of the eight genetic materials. In general, all of then performed well for charcoal production, attending the general expected values for the following properties, with an except to ash content (Loureiro et al., 2019; Couto et al., 2015). However, to proceed with the selection of the most suitable genotypes, the results were further analyzed by the principal component analy sis.

Table 2. Charcoal yield, density, fixed carbon, friability, higher heating value, ash content, fixed carbon yield and energy density.

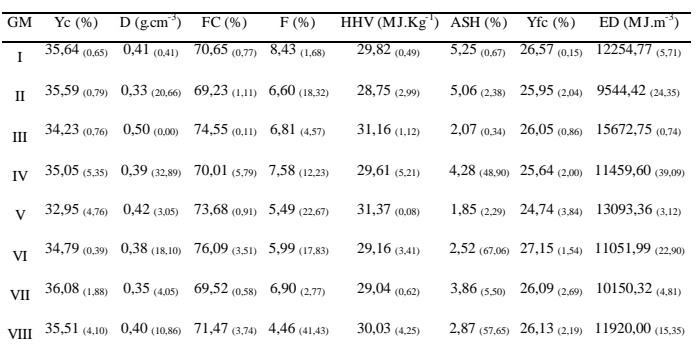

Legend: Values in parentheses represent coefficient of variation. $\mathrm{GM}=$ Genetic materials, $\mathrm{Yc}=$ Charcoal yield, $\mathrm{D}=$ relative apparent density, $\mathrm{FC}=$ fixed carbon content, $\mathrm{F}=$ friability, $\mathrm{HHV}=$ higher heating value of charcoal, $\mathrm{ASH}=$ ash content, $\mathrm{Yfc}=$ fixed carbon yield, $\mathrm{ED}=$ energy density of charcoal.

Table 3 shows the result of the principal component analy sis obtained for the combination of charcoal properties. The variables analyzed were friability (\%), fixed carbon yield

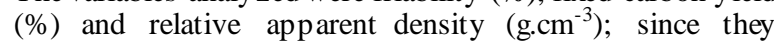


summarize the ideal characteristics of charcoal for steel industry: resistance, thermo-reducer capacity and energy concentration.

Table 3. Principal component analysis of genetic materials charcoal.

\begin{tabular}{llll}
\hline \multirow{2}{*}{ Parameters } & \multicolumn{2}{l}{ Coefficient } \\
\cline { 2 - 4 } & F1 & F2 & F3 \\
\hline Charcoal Proprieties & & & \\
Friability & -0.558 & 0.729 & -0.396 \\
Fixed Carbon Yield & -0.790 & -0.007 & 0.613 \\
Energy Density & 0.601 & 0.668 & 0.438 \\
$\begin{array}{l}\text { Principal Components } \\
\text { Standard deviation }\end{array}$ & 1.140 & 0.989 & 0.850 \\
Proportion of variance & 0.433 & 0.326 & 0.241 \\
Cumulative proportion & 0.433 & 0.759 & 1.000 \\
\hline
\end{tabular}

The Component 3, which explained $24 \%$ of the total data variation, is the representation of the ideal genetic material to produce charcoal, presenting low friability, high fixed carbon yield and apparent density (Pereira et al. 2013). Therefore, this component was used for clonal selection. Based on the results of the principal component analy sis, through equation 6 it is possible to calculate the scores of the Component 3.

$$
Y_{3}=-0.396 \times F+0.613 \times Y_{f c}+0.438 \times E D
$$

Where:

$\mathrm{Y}_{3}=$ Scores of Component 3

$\mathrm{F}=$ Friability $(\%)$

$\mathrm{Y}_{\mathrm{fc}}=$ Fixed Carbon Yield $(\%)$

$\mathrm{ED}=$ Energy Density of Charcoal $\left(\mathrm{MJ} . \mathrm{m}^{-3}\right)$

The results for component 3 scores are presented in Figure 2 for each genetic material. When selecting genetic materials through principal component analy sis for charcoal production, the suitable are III, VI and VIII, since they presented the major factor scores.

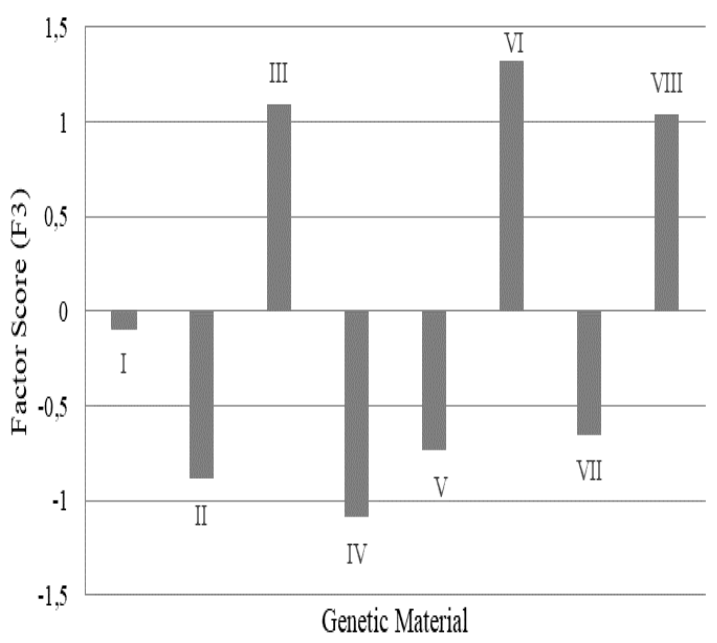

Figure 2. Scores of principal component 3 for selection of superior materials.

\section{Discussion}

Energy density is one of the main properties that define the quality of a genetic material, since it summarizes the amount of heat by volume of the product in a single variable. This is especially important to notice, since material with higher amount of calorific value can perform poorly for energy purposes due to the lower basic density, as seen in genotype VIII. For energetic uses, the combination of these two factors are most relevant than each of them (Chen et al. 2018)

The genetic materials in this study, all presented a high charcoal yield (Fialho et al. 2019; Carneiro et al. 2016; Pereira et al. 2013). However, this propriety by itself isn't enough for genetic materials selection. The balance between the charcoal yield and the other properties, such as friability and fixed carbon content is important, and usually related to the characteristics of the wood (Andrade et al. 2018; Pereira et al. 2012). In this sense, the use of the principal component analy ses allows the study of the gravimetric yield with other fundamental properties for the quality of the charcoal, by observing the relations between them and their impact on the data variation.

The charcoal relative apparent density usually relates to the basic density of wood, as observed for materials I, III and IV. Higher charcoal density lead to greater use in blast furnaces, since the material has longer residence time and greater use of the furnace's volume (Alfaro \& Jones 2018). Nevertheless, this property is also dependent of the carbonization process, once major degradation of the material can lead to lower apparent density and resistance (Somerville \& Jahanshahi 2015).

Fixed carbon content can be attributed to the chemical composition of wood (Carneiro et al. 2016; Mouling et al. 2017), and whose amount in charcoal should be analyzed with caution. Higher amounts of fixed carbon could indicate issue in the pyrolysis process, and the reduction on the process yield (Dufourny et al. 2018).

On the other hand, values below desired for fixed carbon content could indicate that the wood hasn't been carbonized enough, which also shows an inefficient process. This is presented in this study, since only genetic materials III and IV (Table 2) presented fixed carbon y ields closed to the desirable value, between 75 and 80\% (Pereira et al., 2016).

Regarding friability, all the genetic materials presented relatively low values (Table 2), indicating that they could be adequate for ironmaster use. This property is especially important for this use, since the resistance of the charcoals is crucial for the pigiron production in blast furnaces (Dufourny et al. 2018).

Another propriety that is particularly relevant for ironmaster use, regarding the maintenance and lifespan of the furnace, is the ash content of the charcoal, which should be kept under $1 \%$. Ash is composed of minerals, that don't generate energy, and are a residue of difficult disposal for the process (Andrade et al. 2018; Pereira et al. 2013). All the genetic materials of this study present values higher that the ideal (Table 2).

The higher heating value increases in the materials after pyrolysis, and the low values it presents for raw materials is one of the main reasons to thermally treat a woody material (Pereira et al. 2012). This significant increase can be observed from table 1, were HHV of wood varies from 19,11 to 19,61 MJ.Kg ${ }^{-1}$, and table 2 for charcoal from 28,75 to $31,37 \mathrm{MJ} . \mathrm{Kg}$

Energy density is the compilation of the charcoal's density and higher heating value. Essentially, the higher the energy density, more energy is concentrated in the same charcoal mass, therefore, less charcoal is needed for the same process. In terms of process efficiency, this property allows to diminish the load of charcoal transported, which is significant considering the cost of transport (Alfaro \& Jones 2018).

These results allow to select the genetic material based on the proprieties considered the most important combined. Once the energy density of wood was classified by ScottKnott test, genetic material VI was allocated in group 3, for not presenting the highest value, however, when the energy 
density of the charcoal was considered for selection, this particular genotype presents the major score. Thus, the advantage of using principal component analysis in the selection of superior genetic materials is evident. Such a statistical approach, in situations where more than one variable influences the final product, such as charcoal, favors better decision-making in the selection process, since it allows a joint understanding of the impact of these properties on charcoal quality.

As seen in Figure 2, the most suitable genetic materials for charcoal production are III, VI and VIII, since they presented the major factor scores, for the representation of the ideal genetic material, with low friability, high fixed carbon yield and energy density.

\section{Conclusion}

The genotypes selected for energy were the ones in group 1 (V and III), since it presents the highest energy density values, therefore, best use energy generation.

When selecting genetic materials through principal component analy sis for charcoal production, the most suitable ones are III, VI and VIII, since they presented the major factor scores.

\section{Acknowledgements}

To the Foundation for Research of the State of Minas Gerais (FAPEMIG), National Council for Scientific and Technological Development (CNPq), the Brazilian Agricultural Research Corporation (Embrapa Forestas), and the technical support from the Laboratory of Wood Panels and Energy (LAPEM / DEF / UFV).

\section{References}

Alfaro JF, Jones B (2018) Social and environmental impacts of charcoal production in Liberia: Evidence from the field. Energv for Sustainable Development, 47:124-132, 2018. doi: 10.1016/j.esd.2018.09.004

Alves RC, Oliveira ANC, Carrasco EVM (2017) Physical Properties of Eucalyptus cloeziana F. Muell. Floresta $e$ Ambiente, 24(7):1-7. doi: 10.1590/2179-8087.015312

American Societv for Testing and Materials (1997) ASTM D3175-89a: Standard Test Method for Volatile Matter in the Analysis Sample of Coal and Coke. Conshohocken, USA.

American Society for Testing and Materials (2006) ASTM D3174-04: Standard Test Method for Ash in the Analvsis Sample of Coal and Coke from Coal. Conshohocken, USA.

American Society for Testing and Materials (2007) ASTM D240-02: Standard Test Method for Heat of Combustion of Liquid Hydrocarbon Fuels by Bomb Calorimeter. Conshohocken, USA.

Andrade FWC, Filho MT, Moutinho VHP (2018) Influence of Wood Phy sical Properties on Charcoal from Eucalyptus spp. Floresta e Ambiente, 25(8):1-8. doi: 10.1590/21798087.017615

Canadell JG. Schulze ED (2014) Global potential of biospheric carbon management for climate mitigation. Nature communications, 5:1-12. doi: $10.1038 /$ ncomms 6282

Carneiro ACO, Vital BR, Frederico PGU, Fialho LF, Figueiró CG, Silva CMS (2016) Effect of genetic materials and the site in charcoal quality of short rotation wood. Floresta, 46:473-480. doi: 10.5380/rf.v46i4.45704

Chen Z. Wang M. Jiang E. Wang D. Zhang K. Ren Y. Jiang Y (2018) Pyrolysis of Torrefied Biomass. Trends in Biotechnology, 36(12):1287-1298. doi: 10.1016/j.tibtech.2018.07.005.

Couto AM, Trugilho PF, Napoli A, Lima JT, da Silva JRM, Protásio TP (2015) Ouality of charcoal from Corv mbia and Eucalyptus produced at different final carbonization temperatures. Scientia Forestalis, 43(108):817-831. doi: dx.doi.org/10.18671/scifor.v43n108.7

Dufourny A, Van De Steene L, Humbert G, Guibal D, Martin L. Blin J (2018) Influence of pvrolvsis conditions and the nature of the wood on the quality of charcoal as a reducing agent. Journal of Analytical and Applied Pyrolysis, 19:113. doi: $10.1016 /$ j.jaap.2018.10.013

Fialho LF, Carneiro ACO, Figueiro CG, Carneiro APS, Surdi P. Vital VR. Magalhães MA. Peres LC (2019) Application of thermogravimetric analysis as a pre-selection tool for Eucalyptus spp. Revista Brasileira de Ciências Agrárias, 14:1-9. doi: 10.5039/agraria.v14i3a6363

Granato D, Santos JS, Escher GB, Ferreira BL, Maggio RM (2018) Use of principal component analysis (PCA) and hierarchical cluster analysis (HCA) for multivariate association between bioactive compounds and functional properties in foods: A critical perspective. Trends in Food Science \& Technology, 72:83-90. doi: 10.1016/j.tifs.2017.12.006

Loureiro BA, Vieira TAS, Costa LJ, Silva AB, de Assis MR, Trugilho PF (2019) Selection of superior clones of Corymbia hybrids based on wood and charcoal properties. Maderas. Ciencia v tecnología, 21(4). doi: 10.4067/S0718221X2019005000417

Mouling JC, Nobre JRC, Castro JP, Trugilho PF, Arantes MDC (2017) Effect of extractives and carbonization temperature on Energy characteristics of wood waste in amazon rainforest. Cerne. 23:209-218. doi: $10.1590 / 01047760201723022216$

Pereira BLC, Carneiro ACO, Carvalho AMML, Colodette JL Oliveira AC, Fontes MPF (2013) Influence of Chemical Composition of Eucalyptus Wood on Gravimetric Yield and Charcoal Properties. BioResources, 8:4574-4592. doi: $10.1590 / 2179-8087.017615$

Pereira BLC, Carvalho AMML, Oliveira AC, Santos LC, Carneiro ACO, Magalhães MA (2016) Effect of wood carbonization in the anatomical structure and density of charcoal from Eucalvptus. Ciência Florestal, 26:545-557. doi: $10.5902 / 1980509822755$

Pereira BLC, Oliveira AC, Carvalho AMML, Carneiro ACO, Santos LC, Vital BR (2012) Quality of Wood and Charcoal from Eucaly ptus Clones for Ironmaster Use. International Journal of Forestry Research, 2012:1-8. doi: $10.1155 / 2012 / 523025$

Rambo MKD, Rambo MCD, Almeida KJCR, Alexandre GP (2015) Study of thermo-gravimetric analysis of different lignocellulosic biomass using principal component analvsis. Ciência e Natura, 37:862-868. doi: $10.5902 / 2179460 \times 18332$

Somerville M, Jahanshahi S (2015) The effect of temperature and compression during py roly sis on the density of charcoal 
made from Australian eucalvpt wood. Renewable Energy, 80(8):471-478. doi: 10.1016/j.renene.2015.02.013

Welfle A (2017) Balancing growing global bioenergy resource demands - Brazil's biomass potential and the availability of resource for trade. Biomass and Bioenergy, 105:83-95. doi: 10.1016/j.biombioe.2017.06.011

Wendling I, Brooks PR, Trueman SJ (2015) Topophysis in Corymbia torelliana $\mathrm{x}$ C. citriodora seedlings: adventitious rooting capacity, stem anatomy, and auxin and abscisic acid concentrations. New Forests, 46:107-120. doi: 10.1007/s11056-014-9451-7 